University of Nebraska - Lincoln

DigitalCommons@University of Nebraska - Lincoln

Congreso internacional sobre iconografía

precolombina, Barcelona 2019. Actas.

8-20-2020

\title{
La fascinante revelación de las formas esquemáticas precolombinas
}

Luz Helena Ballestas Rincón

Follow this and additional works at: https://digitalcommons.unl.edu/actas2019

Part of the American Material Culture Commons, Indigenous Studies Commons, Museum Studies Commons, Other History of Art, Architecture, and Archaeology Commons, and the Other Languages, Societies, and Cultures Commons

This Article is brought to you for free and open access by the Zea E-Books at DigitalCommons@University of Nebraska - Lincoln. It has been accepted for inclusion in Congreso internacional sobre iconografía precolombina, Barcelona 2019. Actas. by an authorized administrator of DigitalCommons@University of Nebraska - Lincoln. 


\title{
La fascinante revelación de las formas esquemáticas precolombinas
}

\author{
Luz Helena Ballestas Rincón
}

Profesora Asociada Universidad Nacional de Colombia. Facultad de Artes, Escuela de Diseño Gráfico. lhballestasr@unal.edu.co

\section{Resumen}

No hay duda de que las formas son un vehículo de comunicación. En el mundo precolombino, ciertas formas fueron codificadas hasta el punto de representar en signos aspectos relevantes para la sociedad.

Algunas son de tipo esquemático, por lo cual muchas veces se han determinado como "ornamentales" sin embargo, en la cultura material, formas básicas del diseño como son el círculo, la cruz y la espiral, tuvieron simbolismo implícito que quizás se escapa a nuestra percepción pero que podrían provenir de los atributos de seres de la naturaleza o de los objetos. Mediante el reconocimiento y el análisis de la síntesis visual de los objetos y la gráfica, se logra evidenciar que bajo estas formas codificadas subyacen estructuras que definen su carácter comunicativo.

Palabras clave: Formas esquemáticas precolombinas y comunicación, Signos precolombinos y simbolismo

\begin{abstract}
There is no doubt that forms are a vehicle of communication. In the pre-Columbian world, certain forms were coded to the point of representing aspects relevant to society.

Some are of a schematic type, which is why they have often been determined as "ornamental," however, in material culture, basic forms of design such as the circle, the cross and the spiral, had implicit symbolism that perhaps escapes our perception but that could come from the attributes of beings of nature or objects. Through the recognition and analysis of the visual synthesis of objects and graphics, it is possible to show that under these coded forms underlying structures that define their communicative nature.
\end{abstract}

Keywords: Pre-Columbian schematic forms and communication, Pre-Columbian signs and symbolism

\section{Las formas esquemáticas precolombinas}

La fascinación es ese fenómeno derivado de la percepción, que opera a través de nuestros ojos y nos atrapa, nos seduce y nos provoca el deseo de obtener respuestas. Y es fascinante que algunos motivos esquemáticos precolombinos, desde la perspectiva del diseño gráfico, puedan ser analizados en sus estructuras o bien como signos, los cuales podrían llevar implícito algún sentido o son la representación analógica de algún ente u objeto.

En el diseño, las formas esquemáticas básicas son: el círculo, el cuadrado y el triángulo; con ellas se pueden obtener todas las variables posibles para diseñar ${ }^{1}$. Cada una tiene atributos morfológicos diferentes y pueden provocar relaciones perceptivas diversas, que en casos sugieren, por analogía, síntesis de elementos naturales, círculo - sol, u objetuales, círculo - plato, por ejemplo. En el diseño precolombino, también son básicas la espiral, el escalonado y el zigzag, conclusión a la que llegamos mediante la investigación sobre las formas esquemáticas en la cerámica de México, Perú y Colombia.

Así, hemos establecido dos categorías de análisis para la gráfica precolombina: Formas radiadas: cruz, círculo, estrella y espiral y formas angulares: cuadrado, triángulo, escalonado y zigzag. Para obtener información sobre la asignación de sentido de estas formas fue necesario buscar las relaciones existentes no sólo en el plano

1. Joan Costa (1997) agrega como figuras básicas, si de marcas se trata, la cruz y la estrella.

Publicado en Congreso internacional sobre iconografía precolombina, Barcelona 2019. Actas, Victòria Solanilla Demestre, editora (Lincoln, Nebraska: Zea Books, 2020). https://doi.org/10.32873/unl.dc.zea.1253 


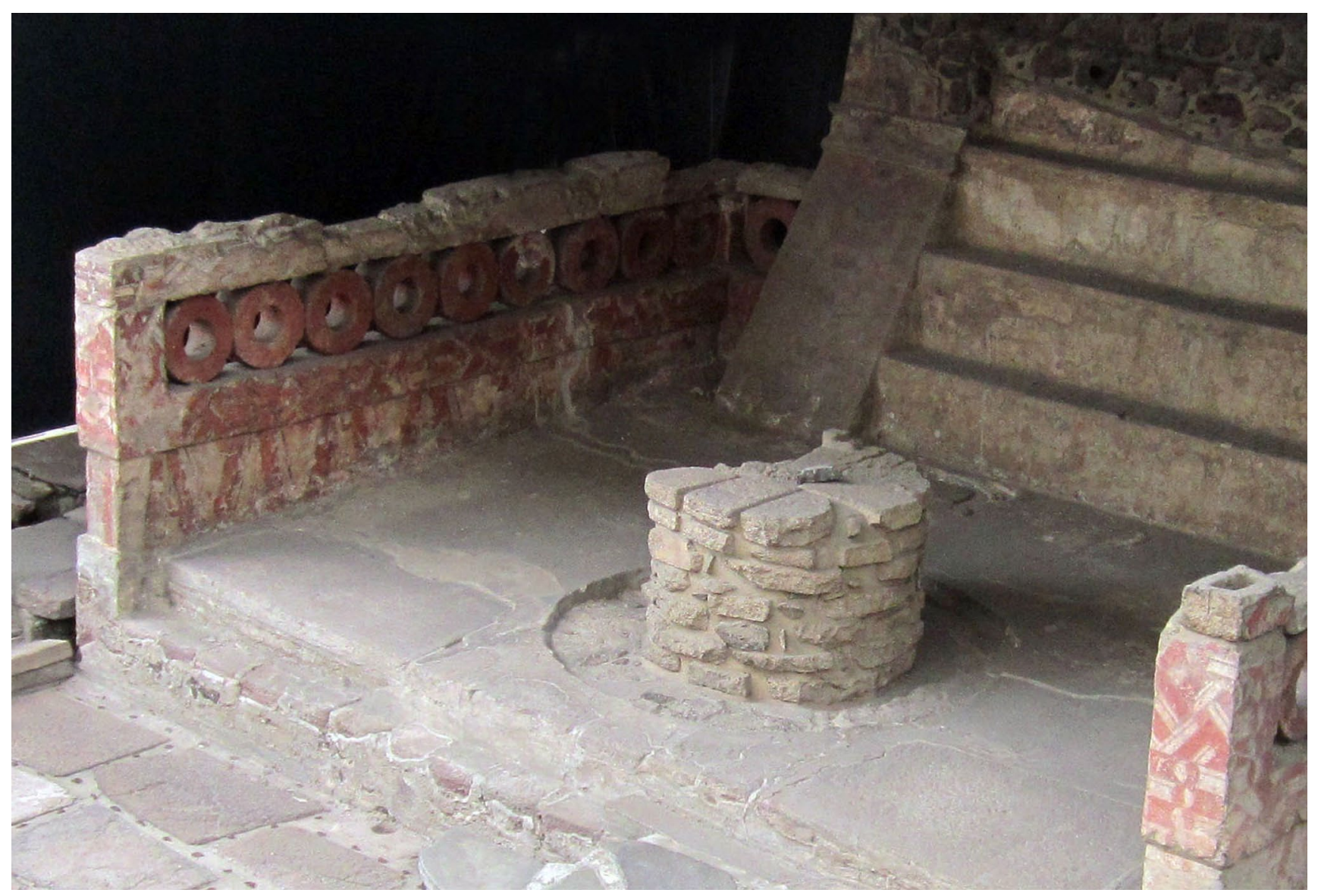

Figura 1. Muro en el Templo Mayor. México. ${ }^{2}$

bidimensional sino en otros ámbitos de la cultura material, tales como la arquitectura y los objetos tanto cotidianos como rituales, entre estos los textiles y el vestuario usados en las prácticas sociales, aunque la cantidad y la frecuencia de uso no siempre son similares.

Las formas a las cuales dirigimos nuestro estudio, debido quizás a su esquematismo, han pasado desapercibidas y es posible que se hayan determinado como "ornamentales"; aunque podrían serlo, porque parecerían complemento estético de los objetos, ya estén de manera aislada o en repetición modular, podrían representar en algunos casos motivos simbólicos y de esta manera ser portadoras de sentido y por ende vehículo de comunicación.

Para algunas de estas formas esquemáticas seleccionadas para presentar aquí, es posible proponer relaciones de forma y de sentido a través del análisis iconográfico de acuerdo con lo establecido en otros ámbitos u objetos, en conjunto con lo revelado estructural y comparativamente.

\section{Círculo}

En el repertorio de formas precolombinas destaca el círculo. Comúnmente está en la morfología de vasijas, platos y volantes de huso. Además está presente en orejeras, coronas, tocados y diademas en México, Perú y Colombia. En Perú está en escudos, aunque también los hay cuadrados y en México está en los escudos de guerrero, chimalli como el que reposa en el Museo Nacional de Antropología que está cubierto de plumas y tiene un diseño espiral escalonado de gran significación simbólica. En los marcadores del juego de la pelota del antiguo México también está pero lo relevante es que el círculo con un espacio en el interior, el chalchihuite fue de gran importancia jerárquica. Es considerado la "piedra preciosa" porque hace referencia a las cuentas de collar ya sean de jade, obsidiana o turquesa. Como signo codificado, se vinculó con lo bello y se utilizó en contextos de alta jerarquía, en consecuencia, está en los más variados objetos entre

2. Excepto las fotografías en las figuras 2 y 8, las demás fueron tomadas por Luz Helena Ballestas. 


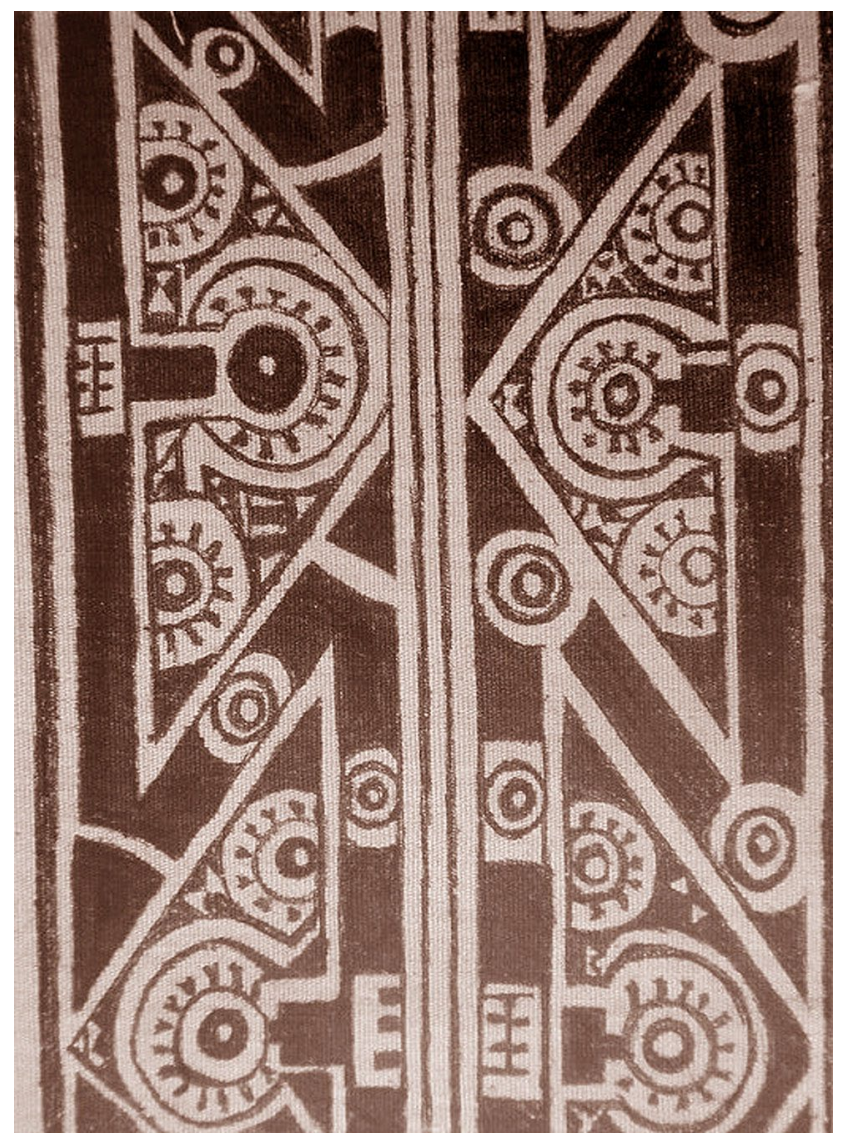

Figura 2. Textil Muisca. Colombia. Tomado de: Jiménez de Muñoz (2009).

ellos sillas, como las que muestra el Codice Borgia y en incensarios. En la arquitectura está presente en los espacios sagrados o ceremoniales como se pueden observar en el Codice Nuttall. Así mismo está en pinturas murales de Teotihuacán, pero lo más interesante es que están en uno de los muros de un recinto del Templo Mayor, Figura 1. Llama la atención que siendo un objeto concebido para ser ensartado no se represente unido a otros por una cuerda, ni se represente en línea, lo que indica que cada uno de ellos fue valorado como pieza única.

En textiles y en el arte rupestre de la región Muisca de Colombia, la forma circular concéntrica radiada es usual, sin embargo, cuando tiene dos segmentos de mayor longitud, estaría implícita lo que podría ser la cabeza de un ave vista de perfil, Fig. 2. Las aves fueron de gran importancia simbólica para este grupo social considerando la cantidad de representaciones en objetos pequeños formados con hilos de tumbaga, una aleación de oro y cobre,

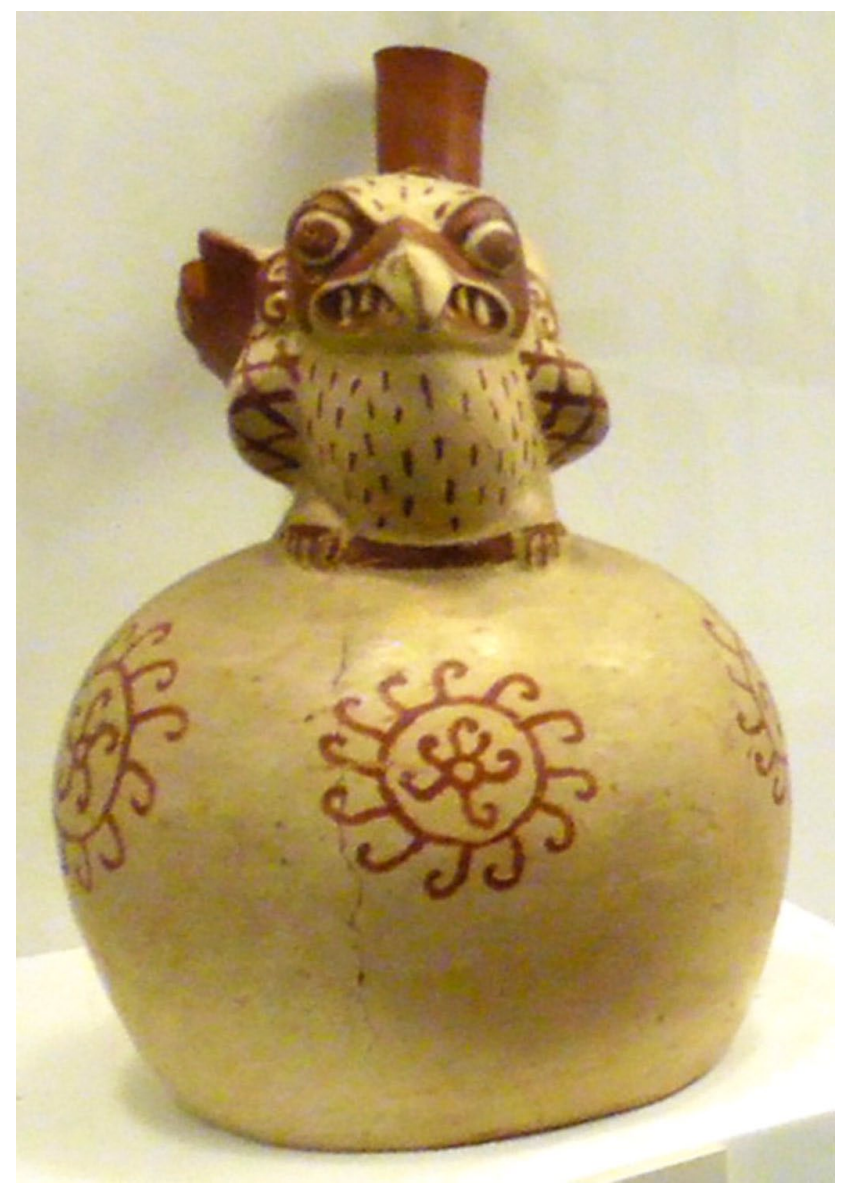

Figura 3. Vasija Moche. Museo Banco Central de la Reserva. Perú.

que por derivación metafórica se ha propuesto como la representación del dios sol, Sua en lengua muisca ${ }^{3}$.

En el Perú, los Mochicas lo utilizaron a manera de laminillas de metal sobre textiles, blusas, turbantes etc., $\mathrm{y}$ en la comunidad Virú lo usó en coronas metálicas. Aunque algunas son rectangulares, es posible suponer que agregaron algo muy importante en las prácticas rituales: el sonido.

Entre las formas circulares, también del Perú, se encuentra una peculiar: el círculo rodeado de volutas, Figura 3. Se puede observar en cerámicas Virú y aparece de manera reiterada en objetos Moche. Para dilucidar qué representaría, tuvimos en cuenta algunos objetos de culturas costeras, como un barco de totora Virú o una la cerámica Nasca que representa un molusco, también está en los sonajeros metálicos que tienen la figura repujada con un rostro interior que reposan en el Museo Larco de Lima y de los cuales se dice que: "estos instrumentos 


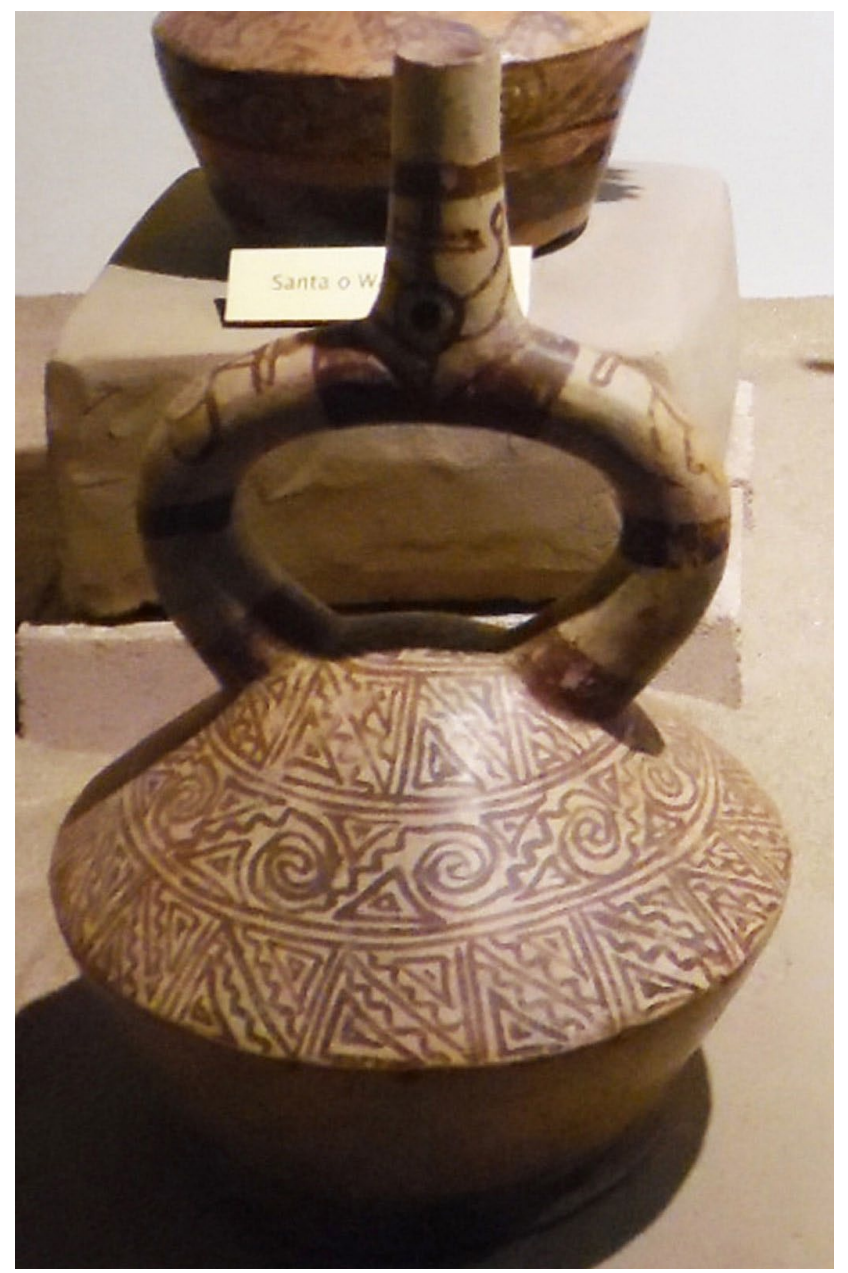

Figura 4. Vasija Moche. Museo Larco Herrera, Lima Perú.

musicales representan animales como pulpos, anémonas rostros de búhos y otros seres mitológicos" ${ }^{4}$, una interpretación.

Así mismo, se tuvo en cuenta vasijas globulares con asa en estribo y una vertedera que se exhibieron categorizadas como objetos marinos ${ }^{5}$ en el Museo Nacional de Colombia, para proponer que dichos círculos radiados con volutas representan seres marinos.

\section{Cuadrado}

Otra forma peculiar que fue reiterativa es el cuadrado con división diagonal. Está en cerámicas en disposición modular lineal y en figuras antropomorfas ya sea en los

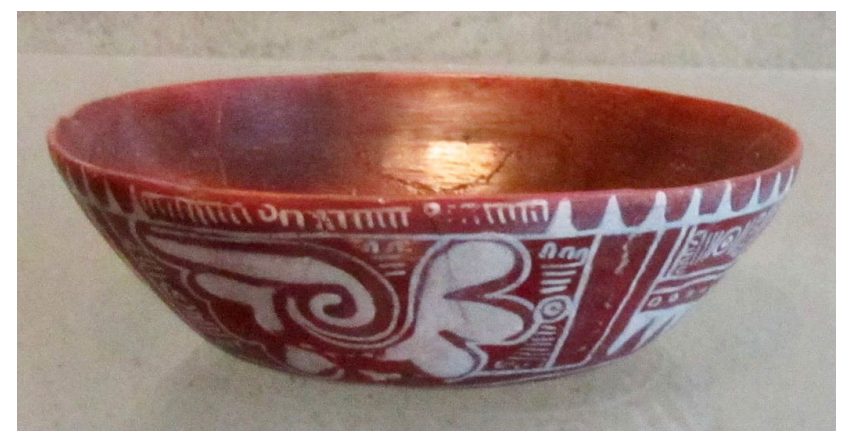

Figura 5. Plato hondo del Estado de México. Museo de Tlatelolco, México.

bordes del vestido o en los brazos y muñecas, Figura 4. Si tenemos en cuenta la estructura triangular generada por la diagonal, comparada con formas de nivel iconográfico medio de la manta raya, se podría deducir su presencia simbólica como signo identificador dual de este ser marino. Una manera de verificarlo es observando algunas cerámicas donde aparece bastante esquemático, pero otra lo muestra con dos elementos interiores que parecen ojos y boca. Por lo que se evidencia la representación de la manta raya de manera esquemática.

\section{Espiral}

Hay formas de gran belleza como la espiral lobulada que está en vasijas de Tlatelolco con variables formales que podrían tratarse de representaciones del "caracol cortado", Figura 5. Así la estrella con espiral interior de vasijas Cempoala de Veracruz también podrían representarlo, dada la estructura que surge del corte transversal del caracol que puede ser interpretada visualmente con formas redondeadas o en punta. Por otro lado, hay algunos caracoles cortados, como los de una urna funeraria del Estado de México que son bastante esquemáticos, tomando forma de estrella recortada por el lado superior, bordean la forma. Es interesante recordar que el caracol cortado fue un determinativo de Quetzalcóatl.

Otra espiral, la que se devuelve sobre la escala, debió tener un valor simbólico importante para los Moche debido a la gran cantidad de vasijas pintadas con este signo y a que se usó en la pintura corporal, especialmente en el rostro, Figura 6. La vinculación simbólica probablemente esté ligada a la serpiente y sus atributos, de acuerdo con

\section{Catálogo del Museo Larco 2010:235.}

5. Nos referimos a la exhibición, El señor de Sipán, donde aparece el motivo en un grupo de vasijas con motivos marinos. Museo Nacional de Colombia en el año 2007. 


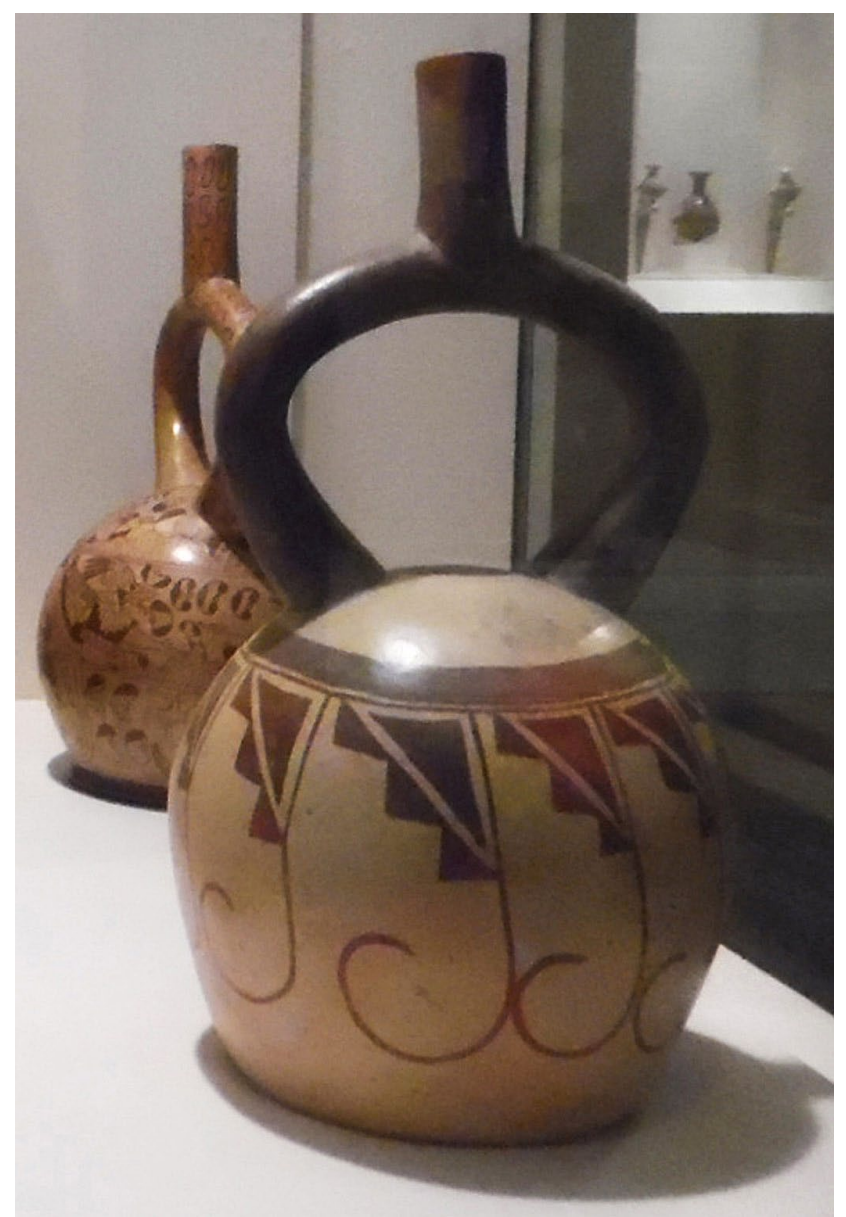

Figura 6. Vasija globular Moche. Museo de América Madrid.

el diseño en una vasija que reposa en el Museo de América de Madrid, cuya gráfica espiraloide termina en una cabeza de serpiente.

\section{Escalonado}

Como es sabido, lo escalonado constituyó una solución efectiva para la construcción de pirámides precolombinas como la de Tajín en México o Rumicolca en Perú. Además, fue un recurso adecuado para la agricultura Inca permitiendo sembrar en terrenos escarpados. Pero no deja de ser interesante que las formas escalonadas estuvieron relacionadas con el poder y las altas jerarquías como lo revelan las sillas y los dinteles pintados en el códice Borgia. Está vinculado con los espacios sagrados, como se puede observar en la cerámica Chimú de la Figura 7 o las representaciones del templo destinado para la ceremonia del fuego nuevo del códice Borbónico

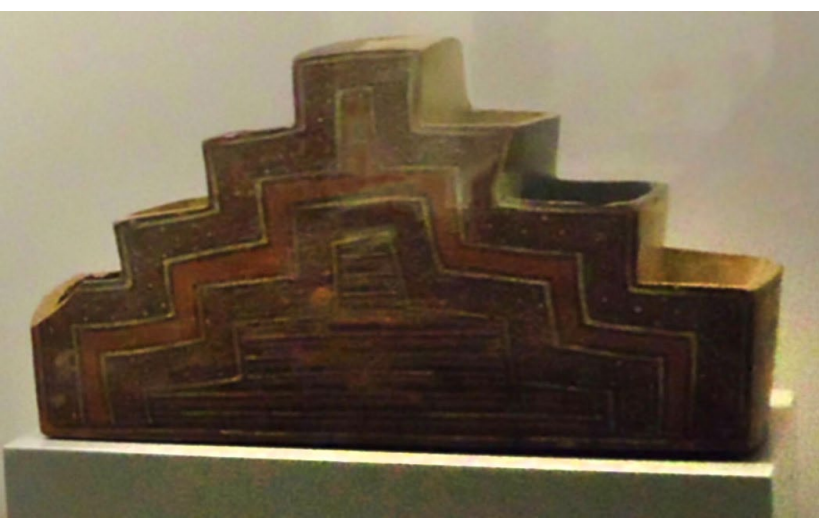

Figura 7. Cerámica Chimú que representa un espacio sagrado. Museo de América Madrid.

y también en la montaña sagrada del códice Nuttall. No obstante, también aparece en objetos cotidianos por ejemplo en vasijas y vasos Nasca y representaciones de vivienda en cerámicas Moche del Perú o mostrando diseños textiles en figuras antropomorfas Tumaco - La Tolita de Colombia y Ecuador.

Es importante anotar que en el lenguaje de las formas, la línea escalonada tiene implícito el ritmo y sugiere la acción de ascender y la conexión entre lo bajo y lo alto.

\section{Zigzag}

Finalmente la línea angular o zigzag, que ha estado vinculada con el movimiento de la serpiente o con el aspecto de su piel. Hay numerosos ejemplos de esto en los vasos rituales Tairona y en la orfebrería Muisca de Colombia, así como, en cerámicas Inca y Nasca del Perú. También está en sellos Mayas y en textiles Paracas del Perú en el cuerpo de serpientes míticas que van a lado y lado de figuras antropomorfas. Se aprecia alrededor del cuerpo o en los bordes de vasijas, en ocasiones con puntos, triángulos o cuadrados en los vanos del zigzag, como en las cerámicas antropomorfas Tairona, Figura 8.

Se podría entonces deducir que esta configuración fue un motivo codificado y de carácter simbólico, derivado de las particularidades morfológicas y actitudinales de la serpiente. Así, es posible que en la pintura corporal usada en los ritos y ceremonias integraran al motivo zigzag, de manera directa o metafórica, los atributos del ofidio y su representación en síntesis formal, como lo observamos en la pintura corporal de figuras antropomorfas del occidente de México. 


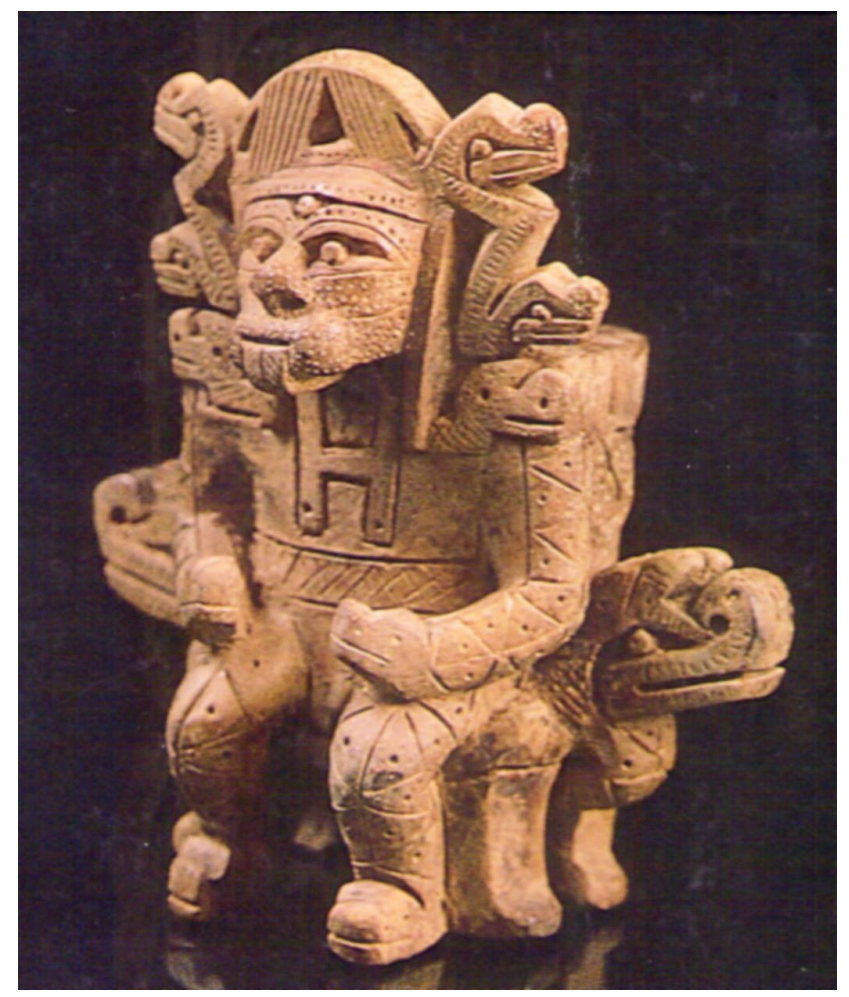

Figura 8. Vaso antropozoomorfo Tairona. Tomado de: Colección Arte de la tierra (1992). Museo Marqués de San Jorge, Bogotá, Colombia.

Es interesante mencionar aquí, que en Colombia aún se utilizan diseños angulares en la pintura corporal de la comunidad indígena Embera, denominados pintura de culebra o pintura de boa mítica, igualmente en los diseños tejidos en la mochila de la comunidad Arhuaca en la cual se representa a la serpiente y su movimiento.

\section{Palabras finales}

Sean estos pocos casos, para revelar que ciertas formas esquemáticas pueden tener un origen naturalista derivado de la síntesis visual analógica que podrían devenir en signos codificados que definirían su carácter simbólico. No obstante, es necesario advertir, que las representaciones esquemáticas, pertenecen a un contexto particular en el cual se codificaron por lo cual, los diversos aspectos culturales podrían ser entendidos por la transferencia de valores que corresponden a los atributos formales o de comportamiento si se trata de la fauna, y que su simbolismo algunas veces puede ser claro y otras veces está implícito.
Podemos constatar que estas formas esquemáticas estuvieron codificadas porque existen formas volumétricas que confirmarían su carácter simbólico lo mismo que, la pericia técnica de los que las crearon: la vasija cocha para libaciones rituales de los incas, que se compone de tres compartimientos circulares interconectados, con salida para el líquido de tres cánulas en el círculo exterior, también las hay en cruz como las vasijas Paquimé de México y hay otra vasija en forma de cruz en disposición horizontal, estilo Nievería, que se encuentra en el Museo Nacional de Arqueología, Antropología e Historia del Perú en Lima. También hay cerámicas escalonadas Chimú que representan espacios sagrados (Fig. 7). Las hay también de morfología espiral: la espiral cuadrada escalonada Nasca con doble vertedera que tiene pintado en la superficie un combate, y un recipiente Moche con vertedera exterior cuya forma espiral se devuelve sobre una configuración escalonada ${ }^{6}$.

\section{Bibliografía}

BALLESTAS RINCÓN, Luz Helena. 2014. Las representaciones implícitas en las formas esquemáticas prehispánicas. Un enfoque gráfico comparativo de la cultura material de México y Colombia. Programa de Maestría y Doctorado en Estudios Mesoamericanos. Universidad Nacional Autónoma de México. México. http://www.posgrado.unam.mx/mesoamericanos/index.php?page=libro-las-representacionesimplicitas-en-las-formas-esquematicas-prehispanicas\#. XM-7s-hKj4Y).

BALLESTAS RINCÓN, Luz Helena. 2011. La representación de la serpiente en la época precolombina. Aproximación desde el diseño Gráfico. En: las imágenes precolombinas reflejo de saberes. María del Carmen Valverde Valdés, Victòria Solanilla (coordinadoras). Universidad Nacional Autónoma de México. México,

BALLESTAS RINCÓN, Luz Helena. 2007. La serpiente en el diseño indígena colombiano. Colección sin condición 13. Universidad Nacional de Colombia. Facultad de Artes. Bogotá.

CAMPANA, Cristóbal. 1983. La vivienda Mochica. Varese S.A. Trujillo, Perú,

COSTA Joan. 1997. El marcaje y la marca En: Imagen global. Enciclopedia de diseño. Ediciones CEAC, S.A. Barcelona, España.

CUESTA, DOMINGO, Mariano. 1980. Cultura y cerámica Mochica. Museo de América. Ministerio de Cultura. Madrid España. 
JIMÉNEZ DE MUÑOZ, Edith. 2009. La representación del ave símbolo del dios Sua. Fundación Universidad de América. Colección hilando memoria indígena. Bogotá.

NUTTALL, Zelia. 1975. The codex Nuttall. A picture manuscript from ancient México. Dover Publications, Inc. New York.

PARDO, Cecilia. FUX, Peter. Editores. 2017. Catálogo Exposición Nasca. Museo de Arte de Lima MALI. Museo Rietberg de Zurich.

SELER, Eduard. 1963. Códice Borgia. Reproducción facsimilar y Láminas explicativas. Fondo de Cultura Económica. México-Buenos Aires.

SPRANZ, Bodo. 1993. Los dioses en los códices mexicanos del grupo Borgia. Fondo de Cultura Económica. México.

ULLOA, Astrid. Kipará. 1992. Dibujo y pintura dos formas Embera de representar el mundo. Centro Editorial Universidad Nacional de Colombia. Bogotá.

\section{Otras fuentes}

Colección Tesoros Precolombinos. Arte de la tierra. Fondo de Promoción de la Cultura Banco Popular. Bogotá, Colombia, 1992. Nariño: 1992. Muiscas y Guanes: 1989. Culturas de Calima: 1989. Tairona: 1991.

Museo Larco. 2010. Tesoros del antiguo Perú. Museo Arqueológico Larco Herrera. Asociación Rafael Larco Hoyle. Lima-Perú.

Catálogo Exposición Sipán. El último tesoro de América. Museo Nacional de Colombia. Bogotá, Colombia, Mayo 17 Agosto 31 de 2007.

Guía para Museos de Arqueología Peruana. Editorial Milla Batres. Lima, Perú, 1983.

Publicaciones del Museo del Oro (Boletines, folletos y otros s/f). 